\title{
Ética, preconceito e educação: características das publicações em periódicos nacionais de educação, filosofia e psicologia entre 1970 e 2003
}

\author{
Alessandra de Morais Shimizu \\ Faculdade de Ciências da Saúde de Garça \\ Ana Paula Cordeiro \\ Universidade Estadual Paulista \\ Maria Suzana De Stefano Menin \\ Universidade Estadual Paulista
}

\section{Introdução}

Esta pesquisa tem como objetivo realizar um estudo bibliográfico quantitativo referente ao tema Ética e preconceito no âmbito da educação escolar. A ocorrência do tema será observada em periódicos nacionais das áreas de educação, psicologia e filosofia, publicados entre a década de 1970 e o início do ano de 2003.

Os temas Ética e Preconceito têm, com frequiência crescente, sido foco de discussões no panorama educacional brasileiro. Envolvem múltiplas questões relacionadas a valores, educação moral, pluralidade de etnias, interculturalidade, racismo, educação inclusiva, entre outras. No âmbito da educação formal, atualmente, esses temas vêm recebendo uma atenção especial devido às suas possibilidades de inserção como transversalidade no currículo escolar. No entanto, ainda suscitam muita controvérsia, pois entre pesquisadores, pais e educadores não existe um consenso sobre questões como "a escola deve educar moralmente?", "como fazê-lo?" e "de acordo com quais valores?".
Segundo Subirats (2000), passamos por um processo de ruptura dos modelos produtivos tradicionais da sociedade capitalista, que obriga a criação de uma instituição educacional que realize, consciente e sistematicamente, a transmissão de conhecimentos, habilidades e valores considerados indispensáveis para produzir mudanças no sistema tradicional de produção.

Acompanha essa transformação a ruptura de moldes tradicionais de valores, que ocorre principalmente devido ao excesso de informações contrapostas, transmitidas pela família, pela mídia e pelo mundo do trabalho. Essa quebra acaba por produzir desarranjos nas instituições sociais, pois se, por um lado, as transformações sócio-históricas das últimas décadas propiciaram uma vivência civil supostamente mais democrática e pluralista, por outro, elas têm sido consideradas motivo de instabilidade.

Devido à urgência de estabilização social, a ética e a educação para os valores passaram a representar um dos grandes eixos de preocupação e discussão nos mais diversos campos: político, científico, religioso, midiático e, especialmente, no campo educacional. 
Ao mesmo tempo, a questão da pluralidade cultural também passou a ser foco de atenção, marcando presença, inclusive, em documentos oficiais. DaMatta (1991) identifica, em nossa sociedade, um "mito da miscigenação brasileira", segundo o qual não existiria preconceito racial em nosso país, posto que o Brasil teria sido formado por brancos, negros e índios. A noção divulgada por esse mito é, de acordo com o pesquisador, acrítica e leva a um preconceito velado. Em uma sociedade como a brasileira, seria essa uma forma muito mais eficiente de discriminação, visto que fica implícita nas relações e no imaginário de todos, sem que dela se fale e, como conseqüência, sem que contra ela se lute.

Ainda de acordo com DaMatta (1991), o Brasil não poderia simplesmente negar sua história, efetivamente realizada por portugueses brancos e aristocráticos, que trouxeram ao país um quadro rígido de valores discriminatórios. Ao longo do tempo o preconceito racial foi negado pela sociedade brasileira, por seus meios de comunicação e até mesmo pela escola, disseminando-se a noção de que o país teria como característica uma "cultura uniforme". Dessa forma, o desprezo por muitas culturas "marginais" foi camuflado por uma falsa idéia de igualdade.

Como decorrência dessa idéia, novas propostas educacionais têm buscado frisar a idéia de que vivemos em um país com grande diversidade cultural e racial. Por isso, é necessário reconhecer, valorizar e pesquisar essa enorme variedade cultural brasileira, sem desprezar e ignorar as diversas contribuições que formam a identidade nacional.

Corroborando essa tese, Valente (2001) acredita que o reconhecimento da diversidade das culturas existentes é uma das grandes questões de nossa época, e aponta o caminho necessário para a superação de tensões e conflitos. Ancorando-se na percepção das diferenças étnicas, raciais, de gênero, nacionais, é possível tomar-se o rumo da construção e consolidação de uma sociedade democrática. De acordo com essa perspectiva, o processo educacional, por seu papel na formação humana - que inclui mecanismos de socialização -, tem sido considerado um cam- po estratégico no qual tais propostas deveriam ser desenvolvidas.

Diante dessa realidade, cabe à universidade a função de buscar estabelecer uma ponte entre as necessidades da sociedade e a atuação dos educadores. Nesse sentido, a análise do contexto sócio-histórico da educação no país pode ser um importante passo para que se esboce uma compreensão dos processos inerentes ao distanciamento entre a realidade idealizada pelas políticas educacionais e a vivida na prática e no espaço educacional do país. Neste artigo, observaremos como a educação moral e, conseqüentemente, as questões da ética e da educação para os valores foram se incorporando à escola, ao longo das últimas décadas.

\section{Modelos de educação moral e experiências brasileiras}

Conforme Buxarrais (1997), os diferentes modelos de educação moral são marcados, basicamente, por três tipos de concepções: o "dogmatismo moral", pelo qual a educação está baseada em valores absolutos inquestionáveis e imutáveis, impostos por um poder autoritário de forma coercitiva; o "relativismo moral", pelo qual as normas de conduta e os valores morais são considerados subjetivos e pessoais, não havendo um consenso sobre a melhor forma de agir; e os modelos baseados na "construção racional e autônoma de valores", que buscam o desenvolvimento de situações que facilitem a construção da autonomia do educando e a participação democrática dos vários membros da escola.

No Brasil, cada uma dessas concepções esteve presente em diferentes momentos históricos. De acordo com Lepre (2001), a partir da década de 1960 a educação moral passou a fazer parte do ensino formal, em todos os seus graus e modalidades, como uma disciplina obrigatória curricular.

Essa obrigatoriedade foi criada na época da ditadura militar (instalada pelo Golpe de 1964), por meio do decreto-lei n ${ }^{\circ} 869$, de 12 de junho de 1969, publicado pelo Governo Médici. O objetivo da inclusão dessa 
disciplina no contexto escolar era o de colaborar com a manutenção do modelo social vigente. Tratava-se de um "decreto de obediência", uma forma dogmática de condução da educação moral, constituída por uma matéria doutrinária e disciplinatória que visava a promoção de uma ordem social vinculada aos ideais militares de controle e repressão da sociedade.

Mais de dez anos depois de iniciado o processo de restabelecimento da democracia, o governo Itamar Franco revogou a obrigatoriedade da existência da disciplina educação moral no currículo escolar (lei $\mathrm{n}^{\circ}$ 8.663, de 14 de junho de 1996). Com isso, essa disciplina foi desaparecendo das escolas. Nesse período, a experiência de se vivenciar a educação moral de forma dogmática e imposta resultou na ausência de projetos pedagógicos explícitos, e até mesmo de discussões sobre moral e valores no contexto escolar. Mesmo no ensino formal, predominou então uma concepção relativista e particularista de moral, de acordo com a qual as decisões deveriam ser guiadas mais por parâmetros individuais do que coletivos.

Após um período significativo de silêncio, estudiosos voltam a levantar a necessidade de se educar moralmente. Essa carência explicita-se pela urgência social, impulsionada, principalmente, pelo aumento da violência e da indisciplina no meio escolar, e pela crise de valores morais que atingem a escola tanto em seus objetivos educacionais e procedimentos pedagógicos como nas relações entre seus membros.

Cortina (2003) afirma que contemporaneamente a moral constitui-se num "artigo de primeira necessidade" (p. 17), visto que nossas sociedades avançadas atravessam uma crise de moralidade - não sabemos o que fazer com massas inteiras de excluídos.

Nas últimas décadas, muitas mudanças ocorreram no Brasil e no mundo. Antigos paradigmas educacionais foram substituídos, visto que o sistema educacional brasileiro teve de se adaptar às demandas do capitalismo globalizado. Como reflexo dessas modificações e urgências sociais, foram elaborados os Parâmetros Curriculares Nacionais (PCNs).

No final de 1997, foi apresentada aos educadores a primeira versão dos PCNs, para o primeiro e segun- do ciclos do ensino fundamental, e, em 1998, para o terceiro e quarto ciclos. Tendo como objetivo auxiliar o professor em sua prática educativa, os Parâmetros apresentam-se como uma proposta construtivista de educação, que visa à construção da autonomia e à preparação do educando para o exercício da cidadania. Assim, a escola deve contribuir para a formação de indivíduos éticos e que entendam a diversidade como fator fundamental de nossa sociedade.

A característica inovadora desse documento é que, ao lado das disciplinas curriculares tradicionais, são inseridos temas transversais (ética e pluralidade cultural, saúde, trabalho e consumo, orientação sexual e meio ambiente), que devem ser trabalhados como conteúdo em todas as matérias já existentes, assim como nas demais práticas escolares.

Os temas transversais são considerados, nos PCNs, linhas de conhecimento que atravessam e se cruzam entre as diferentes disciplinas, constituindose em fator estruturador e condutor da aprendizagem. Devem servir de base para potencializar valores, fomentar comportamentos e conceitos, procedimentos e atitudes que respondam às necessidades pessoais e da própria sociedade.

Por intermédio desses PCNs, a educação moral, a ética, os valores e a pluralidade étnica retornam ao contexto e à história da educação brasileira como assunto prioritário. Apresentam-se, até mesmo, como metas principais do desenvolvimento integral do estudante, em uma educação concebida como construção racional e dialógica de valores.

Vislumbramos, com os PCNs, novos horizontes na formação do aluno para uma educação mais comprometida com a autonomia. No entanto, na complexa realidade socioeconômica e cultural brasileira, as intenções neles contidas esbarram em uma diversidade de questões práticas existentes no ambiente escolar e na sociedade, que interferem significativamente sobre a realização de qualquer proposta educacional. Assim, acreditamos que um aspecto importante a ser considerado é a maneira como o conhecimento científico tem contribuído - ou não - para o desenvolvimento e para o modelo de ética e educação moral utilizado no con- 
texto educacional, assim como para a questão da diversidade e do preconceito.

A fim de compreender melhor o desenvolvimento da abordagem desse tema pela universidade e, por extensão, pela sociedade, buscamos identificar o que pesquisadores observaram e estudaram a esse respeito a partir da década de 1970 até os dias atuais.

\section{Metodologia}

A idealização desta pesquisa deu-se a partir de discussões e leituras realizadas pelo grupo de pesquisa "Valores, educação e formação de professores", da Universidade Estadual Paulista (UNESP), campus de Presidente Prudente, nos anos de 2002 e 2003. Partindo do pressuposto de que o que se desenvolve hoje no Brasil em termos de uma educação para a ética, formação de valores e pluralidade cultural tem suas raízes fixadas em décadas anteriores, optamos por realizar um levantamento bibliográfico nos principais periódicos nacionais de educação, filosofia e psicologia dos anos de 1970 até os dias atuais.

Utilizamos como critério de escolha dos periódicos a serem pesquisados a avaliação, no ano de 2002, pelo Sistema de Classificação de Periódicos, Anais, Jornais e Revistas Qualis, divulgado pela Coordenação de Aperfeiçoamento de Pessoal de Nível Superior (CAPES). Em sua maioria, foram selecionados os periódicos de circulação nacional que obtiveram conceitos A e B nessa classificação. O levantamento dos periódicos foi realizado em bibliotecas da Universidade de São Paulo (USP) e da Universidade do Estado de São Paulo (UNESP) no período de maio de 2003 a janeiro de 2004. As bibliotecas visitadas foram: Biblioteca da Faculdade de Ciências e Tecnologia da UNESP, campus de Presidente Prudente; Biblioteca da Faculdade de Filosofia e Ciências da UNESP, campus de Marília; Biblioteca do Instituto de Psicologia, Biblioteca da Faculdade de Educação e Biblioteca Central da USP. A base de dados do SciELO também foi consultada, no caso de revistas nele indexadas.

As revistas contempladas pela pesquisa foram: Cadernos CEDES; Cadernos de Pesquisa; Educação e Ensino; Educação e Filosofia; Educação e Filosofia de Uberlândia; Educação e Pesquisa; Educação e Realidade; Educação em Revista; Educação e Sociedade; Em Aberto; Ensaio, Avaliação, Política Pública e Educação; Episteme; Estudos de Psicologia; Interface; Leitura: Teoria e Prática; Letras de Hoje; Manuscrito; Psico; Psicologia da Educação; Psicologia em Estudo; Psicologia. Reflexão e Crítica; Psicologia USP; Psicologia: Teoria e Pesquisa; Revista Brasileira de Educação; Revista Brasileira de Estudos Pedagógicos; Revista da Faculdade de Educação da USP e Veritas.

As palavras-chave utilizadas para a pesquisa nos periódicos foram: ética vs. educação; moral vs. educação; desenvolvimento moral vs. educação; valores vs. educação; valores morais vs. educação; desenvolvimento moral vs. ensino fundamental; valores religiosos vs. educação; práticas escolares vs. religião; educação religiosa $v s$. valores; moral $v s$. escola $v s$. religião; preconceito vs. educação; racismo vs. educação; exclusão social $v s$. educação; estereótipos $v s$. educação; estigma vs. educação; diversidade cultural vs. educação; multiculturalismo vs. educação; etnia $v s$. educação; educação inclusiva; preconceito vs. educação especial; preconceito vs. educação inclusiva; preconceito $v s$. pessoas portadoras de necessidades especiais; preconceito vs. deficiência vs. educação; integração social vs. necessidades especiais.

No total, foram encontrados 570 textos que atendiam aos critérios descritos, relativos às palavraschave, aos anos de circulação e aos periódicos selecionados.

Foram analisados os resumos dos textos encontrados; as publicações mais antigas, que não os possuíam, foram analisadas na íntegra. Cada texto foi categorizado para a montagem de um banco de dados. Os elementos enfocados nessa categorização foram: tema do texto, título, revista, autor, palavras-chave, volume, número, data, páginas, tipo de publicação, tipo de estudo, objeto de estudo, metodologia utilizada, sujeitos da pesquisa e número de sujeitos pesquisados. Os dados categorizados foram tabulados de forma a propiciar cruzamento de informações. 
Por meio da análise dos dados, foi possível levantar os seguintes aspectos relativos aos trabalhos pesquisados, os quais serão abordados neste texto: número de artigos sobre os temas centrais da pesquisa (Ética e educação e Preconceito e educação); principais subtemas dentro dos temas centrais; número de artigos publicados em cada periódico pesquisado; revistas em que os subtemas foram predominantemente contemplados; época em que os estudos encontrados foram publicados; tipos de publicações mais freqüentes; natureza dos estudos (pesquisa bibliográfica ou empírica); procedimentos utilizados nas pesquisas empíricas; principais populações estudadas e número de sujeitos participantes.

A pesquisa nos periódicos e a tabulação das categorias usadas para analisar os textos foram feitas pelas autoras e por dez alunos ${ }^{1}$ do Programa de Estágio Não-Obrigatório do Curso de Pedagogia da UNESP, campus de Presidente Prudente.

Os 570 trabalhos selecionados estão à disposição para consulta e pesquisa no Departamento de Educação da Faculdade de Ciências e Tecnologia da UNESP, campus de Presidente Prudente, sob a responsabilidade do grupo de pesquisa "Valores, educação e formação de professores".

\section{Resultados: desdobramento dos temas principais em subtemas}

Inicialmente, separamos os 570 trabalhos encontrados em dois grupos, um versando sobre Ética, moral e educação, com 202 títulos (35\% do total), e o outro sobre Preconceito e educação, com 368 estu$\operatorname{dos}(65 \%)$.

Nos textos selecionados, verificamos que tanto a ética como o preconceito aparecem inter-relacio-

${ }^{1}$ Agradecemos o empenho e a dedicação dos estagiários participantes desta pesquisa: Miriam Piquione, Fábio Xavier, Viviane Favareto, Cristiana dos Santos, Magda R. de Almeida, Renata Aparecida Carbone, Aline Pereira Lima, Antônia Margarete Duarte Luna e Marceli Machado Lopes. nados com conteúdos específicos que também fazem parte do contexto educacional. Dessa forma, para fins de organização e realização de futuros estudos qualitativos mais específicos, os textos foram agrupados em subtemas. No entanto, é necessário ressaltar que não os textos não têm assuntos estanques, mas de um modo ou outro inter-ligados, teórica e/ou pragmaticamente.

Dentro do tema Ética, moral e educação (como demonstra o Gráfico 1), os subtemas levantados foram: Ética, valores e educação; Educação moral, desenvolvimento moral e moralidade, e Educação, cidadania e direitos humanos.

Baseados nos termos utilizados pelos próprios autores dos textos selecionados, formamos um subgrupo de textos que abordam a ética, e outro com estudos sobre moral. Advertimos, entretanto, que essa distinção tem apenas uma finalidade pragmática, pois algumas vezes os termos "ética" e "moral" são empregados como sinônimos, e em outras possuem um sentido diferenciado.

Cortina (2003), por exemplo, afirma que a ética é uma parte da filosofia que reflete sobre a moral, recebendo por isso também o nome de filosofia moral:

Ética e moral distinguem-se simplesmente no sentido de que, enquanto a moral faz parte da vida cotidiana das sociedades e dos indivíduos, e não foi inventada pelos filósofos, a ética é um saber filosófico; enquanto a moral tem "sobrenomes" derivados da vida social, como "moral cristã", "moral islâmica" ou "moral socialista", a ética tem sobrenomes filosóficos, como "aristotélica", "estóica" ou "kantiana". (Cortina, 2003, p.14)

Aranguren, citado por Cortina (2003), distingue os termos ética e moral, denominando esta de moral vivida, e a ética de moral pensada, visto que existe um movimento entre esses dois níveis distintos de reflexão, que seriam o cotidiano e o filosófico.

Segundo La Taille, Souza e Vizioli (2004), na linguagem comum as palavras "ética" e "moral" são utilizadas como sinônimos, empregadas para fazer referência a um conjunto de regras e normas que de- 
vem ser seguidas. Já no meio acadêmico, muitas vezes o termo "moral" é empregado para designar valores, princípios e regras legitimados por determinada comunidade, enquanto "ética" designa uma reflexão sobre tais valores, princípios e regras. Outra distinção é que o termo "moral" faz referência ao campo do dever, e "ética" ao da felicidade e virtudes. Mas, esses mesmos autores ressalvam, esse campo de estudo é muito rico e passível de reflexões. Assim, a distinção realizada em nosso estudo é apenas de ordem prática.

Em relação ao número de textos em cada subtema (como demonstra o Gráfico 1), primeiramente temos Ética, valores e educação, com 84 trabalhos ( $41 \%$ do total de títulos sobre Ética, moral e educação), em que estão reunidos estudos sobre as relações entre ética, formação em valores e educação nos diferentes níveis de ensino, e que abordam, mais especificamente, questões como: a ética como tema transversal; os fins da educação ética e em valores na escola; a formação de professores para uma educação ética; o papel dos valores no desenvolvimento infantil; condições que propiciem atitudes de valor na escola; análise da situação ética das escolas. Em seguida, está o subtema Educação moral, desenvolvimento moral e moralidade, com 79 títulos (40\%), englobando estudos sobre relações entre o desenvolvimento do julgamento moral e demais variáveis, dentre elas cognição, afetividade, ambiente escolar; a questão do universalismo e relativismo no julgamento moral; a escola como uma comunidade justa ou injusta; mensuração da competência moral; o papel das instituições como moralizadoras; interações sociais em sala de aula; a educação moral no mundo contemporâneo; disciplina e indisciplina na escola e na sala de aula. Por último, temos o subtema Educação, cidadania e direitos humanos, com 37 trabalhos (19\%), enfatizando aspectos como a educação como direito constitucional do cidadão; o ensino e sua relação com a formação da cidadania; a cidadania em livros didáticos; a igualdade ou desigualdade política dos cidadãos e sua relação com a educação; direitos humanos, cidadania e amplitude da educação.
Gráfico 1 - Freqüência das publicações sobre Ética, moral e educação conforme os subtemas

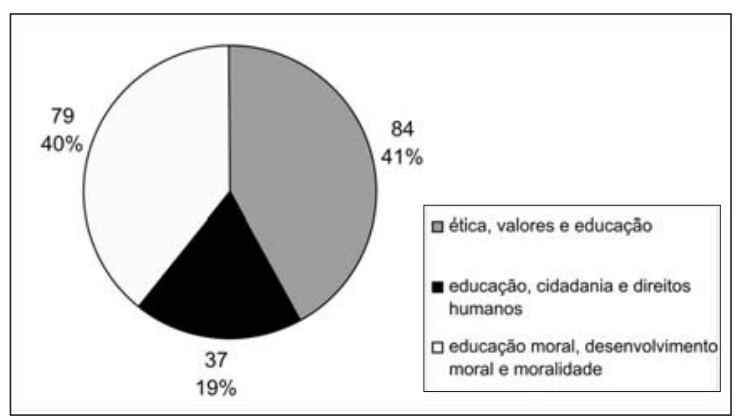

No que tange ao tema Preconceito e educação, os trabalhos foram agrupados nos seguintes subtemas (Gráfico 2): Preconceito racial e étnico e educação, com cem títulos encontrados ( $27 \%$ do total de publicações sobre Preconceito e educação), agrupando-se neste subtema aqueles trabalhos que abordam principalmente o preconceito e a desigualdade racial e étnica no contexto educacional brasileiro, no que tange a questões relacionadas à oportunidade educacional, progressão, repetência e exclusão escolar. Em seguida, com 92 títulos (24,9\%), está o subtema Exclusão social, marginalização, educação e sociedade, focalizando a relação entre a educação e as desigualdades sociais, e o papel da escola ora como reprodutora da exclusão e marginalização social, ora como instrumento de transformação da realidade. Em terceiro lugar, com 85 estudos (23\%), aparece o subtema Preconceito relacionado ao gênero e educação, no qual estão agrupados aqueles trabalhos que evidenciam a problemática dos estereótipos de gênero, da desigualdade do papel masculino e feminino no contexto educacional brasileiro e da diferença de escolaridade entre os sexos. Logo após, aparece o subtema Cultura, multiculturalismo e educação, com 53 títulos (14,3\%), englobando-se neste montante estudos sobre diversidade cultural, identidade cultural e currículo; contradições políticas do multiculturalismo; cultura, globalização e educação; relação entre cultura e escola; o reconhecimento das formas de produção cultural; conceito de cultura; mudanças na sociedade e na cultura e suas implicações na vida escolar; problematização 
das contradições referentes à pluralidade cultural e suas várias expressões no âmbito educacional. Por fim, aparece o subtema Preconceito, pessoas portadoras de necessidades especiais e educação especial, com 40 trabalhos $(10,8 \%)$ que abordam conteúdos sobre o desenvolvimento de atividades e estudos na educação especial; a institucionalização da deficiência; escola pública gratuita para deficientes; processos de aprendizagem de pessoas portadores de necessidades especiais; a educação inclusiva dos alunos com necessidades especiais.

Gráfico 2 - Freqüência das publicações sobre Preconceito e educação conforme os subtemas

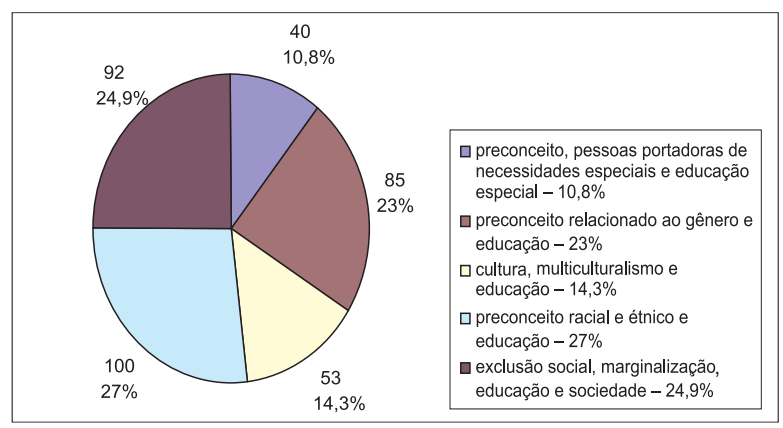

Freqüência com que os textos aparecem nos periódicos pesquisados

Quanto às revistas pesquisadas, a Tabela 1 apresenta as revistas e a freqüência com a qual os títulos selecionados na pesquisa aparecem.

Verificamos que as revistas que publicaram mais artigos voltados à Ética, moral e educação e Preconceito e educação foram: Cadernos de Pesquisa, com 161 publicações (28,2\%); Educação e Sociedade, com 51 trabalhos (8,9\%); Revista Brasileira de Educação, com 50 títulos (8,8\%); Psicologia. Reflexão e Crítica, com 40 trabalhos (7\%); Cadernos CEDES e Revista da Faculdade de Educação da USP, cada uma com 36 títulos (6,3\%). As demais revistas apresentaram uma freqüência menor do que 5\% do total de trabalhos selecionados.

O cruzamento dos dados referentes aos subtemas selecionados e às revistas pesquisadas revelou, entre
Tabela 1 - Número de trabalhos encontrados por revista pesquisada

\begin{tabular}{|l|r|l|}
\hline \multicolumn{1}{|c|}{ Revista } & Freq. & \multicolumn{1}{|c|}{$\%$} \\
\hline Cadernos de Pesquisa & 161 & 28,2 \\
Educação e Sociedade & 51 & 8,9 \\
Revista Brasileira de Educação & 50 & 8,8 \\
Psicologia. Reflexão e Crítica & 40 & 7 \\
Cadernos CEDES & 36 & 6,3 \\
Revista da Faculdade de Educação da USP & 36 & 6,3 \\
Educação e Realidade & 24 & 4,2 \\
Veritas & 23 & 4 \\
Psico & 21 & 3,7 \\
Psicologia em Estudo & 16 & 2,8 \\
Psicologia: Teoria e Pesquisa & 16 & 2,8 \\
Educação em Revista & 15 & 2,6 \\
Educação e Pesquisa & 15 & 2,6 \\
Revista Brasileira de Estudos Pedagógicos & 11 & 1,9 \\
Educação e Filosofia & 4 & 0,7 \\
Educação e Filosofia de Uberlândia & 9 & 1,6 \\
Em Aberto & 8 & 1,4 \\
Letras de Hoje & 8 & 1,4 \\
Leitura: teoria e prática & 6 & 1,1 \\
Psicologia da Educação & 6 & 1,1 \\
Ensaio-Avaliação, Política Pública e Educação & 4 & 0,7 \\
Interface & 3 & 0,5 \\
Manuscrito & 2 & 0,4 \\
Educação e Ensino & 2 & 0,4 \\
Psicologia USP & 2 & 0,4 \\
Epistemé & 1 & 0,2 \\
Estudos de Psicologia & 0 & 0 \\
\hline & 570 & 100,0 \\
\hline
\end{tabular}

os estudos publicados, em quais revistas os diferentes subtemas foram predominantemente contemplados.

Ética, valores e educação é um subtema que aparece de maneira dispersa entre as revistas pesquisadas; no entanto, o maior agrupamento deu-se nas revistas: Revista da Faculdade de Educação da USP, com 17 títulos (20,2\% do total de textos publicados com este subtema); Veritas, com 16 trabalhos (19\%); e Educação e Sociedade, com 12 estudos (14\%). O subtema Educação moral, desenvolvimento moral e moralidade foi encontrado com mais freqüência nas revistas: Psicologia. Reflexão e Crítica, com 26 títulos (32,9\%); Psicologia: Teoria e Pesquisa, com 10 (12,7\%); e Cadernos de Pesquisa com 9 (11,4\%). O subtema Educação, cidadania e direitos humanos aparece com maior freqüência nos Cadernos de Pesquisa, com 9 títulos (24,3\%); na revista Educação e Sociedade, com 7 trabalhos (18,9\%); nos Cadernos 
CEDES, com 5 estudos (13,5\%); e na Revista Brasileira de Educação, com 5 títulos (13,5\%).

O subtema que possui mais títulos na pesquisa, Preconceito racial e étnico e educação, teve seus artigos predominantemente publicados nos Cadernos de Pesquisa, com 49 trabalhos (49\%). Exclusão social, marginalização, educação e sociedade é um subtema mais publicado nesses Cadernos, tendo sido encontrados 30 títulos (32,6\%). Não obstante, outros periódicos também se destacam na publicação de textos nesse campo, como a Revista Brasileira de Educação, contando-se 17 trabalhos (18,5\%), e Educação e Sociedade, com 10 textos (10,9\%). O subtema Preconceito relacionado ao gênero e educação também recebe a sua maior contribuição dos Cadernos de Pesquisa, com 45 títulos $(52,9 \%)$ encontrados somente nessa revista. O subtema Cultura, multiculturalismo e educação aparece com mais freqüência nos periódicos Revista Brasileira de Educação, com 10 trabalhos (18,9\%); Cadernos de Pesquisa, também com 10 títulos (18,9\%); Cadernos CEDES, com 7 (13,2\%); e Educação e Sociedade, com 6 (11,3\%). Em relação ao subtema Preconceito, pessoas portadoras de necessidades especiais e educação especial, os periódicos que apresentaram mais títulos nesse campo são: Cadernos CEDES, com 13 títulos (32,5\%); Revista Brasileira de Estudos Pedagógicos, com 6 trabalhos (15\%); e Psicologia em Estudo, com 5 (12,5\%).

\section{Cronologia das publicações}

Quanto à época em que os trabalhos selecionados foram publicados, podemos perceber que houve um crescimento significativo dessas publicações nas três últimas décadas. Verificamos que enquanto na década de 1970 foram publicados apenas 63 trabalhos ( $11 \%$ do total de textos selecionados), na de 1980 esse número avançou para 181 títulos $(31,8 \%)$, passando para 207 estudos na década de 1990 (36,3\%). Aos anos de 2000 a 2003, pertencem 119 trabalhos (20,9\% do total), o que indica um crescimento significativo no ritmo de publicação de trabalhos relativos à área. Este dado, em uma primeira análise, poderia indicar um aumento do interesse pelo tema, nos últimos anos.

Devemos considerar, no entanto, que não foram somente os temas abordados em nossa pesquisa que apresentaram essa expansão a partir da década de 1980. O país tem vivido, nestas últimas décadas, um incremento da divulgação da produção científica de um modo geral, tendo-se como um dos fatores desencadeadores dessa nova realidade a criação de novos periódicos. Nesse sentido, não se pode deixar de constatar que a maioria das revistas selecionadas em nosso estudo foi lançada nas décadas de 1980 e 1990. Entretanto, quando analisamos a evolução das publicações ao longo do tempo, conforme cada subtema selecionado, percebemos algumas peculiaridades que merecem destaque.

Vejamos, no Gráfico 3, como o número de publicações dos subtemas que se desdobram do grupo Ética, moral e educação foram se modificando de acordo com a época:

Gráfico 3 - Evolução das publicações sobre Ética, moral e educação ao longo do tempo

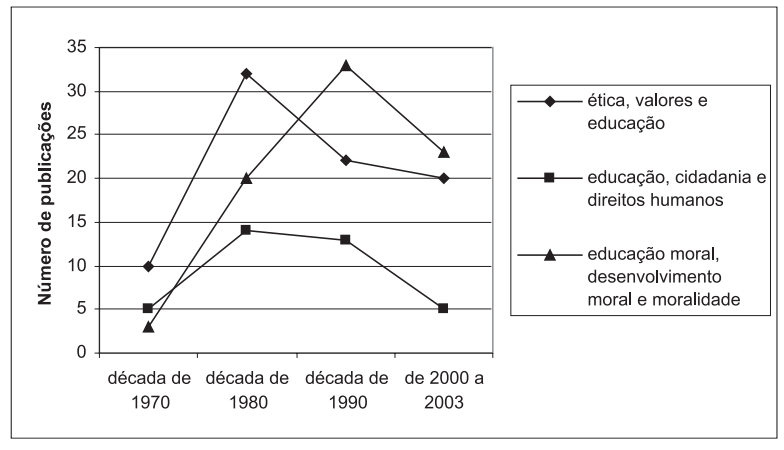

De acordo com o Gráfico 3, há poucas publicações na década de 1970 que abordam os subtemas selecionados. A partir do decênio seguinte, ocorreu um aumento significativo de produções. O subtema Ética, valores e educação, especialmente, foi alvo de grande enfoque nos anos de 1980, com 32 títulos (38,1\% do total de títulos com esse subtema) publicados. Enquanto isso, da década de 1970 foram encontrados 10 títulos (11,9\%), 22 títulos (26,2\%) da década de 1990, e 20 títulos $(23,8 \%)$ a partir do ano 2000. 
Como se afirmou anteriormente, esta pesquisa compreende periódicos publicados até o ano de 2003. Mesmo ao utilizarmos apenas três anos da década de 2000 como termo de comparação às outras duas décadas inteiras compreendidas pelo estudo, surpreende a quantidade de publicações a respeito desse subtema encontradas nesse período: 20 títulos. Proporcionalmente, esses dados parecem revelar o surgimento de um crescente interesse pelo tema nesta nova década.

O subtema Educação, cidadania e direitos humanos, por sua vez, apresentou um avanço importante no número de publicações já na década de 1980 , com 14 títulos (37,8\% do total neste subtema) e na década de 1990, com 13 trabalhos (35,1\%), ficando a década de 1970 e os anos de 2000 a 2003 com cinco títulos cada $(13,5 \%)$. Apesar da porcentagem menor relativa aos anos de 2000 a 2003, não deixa de significar uma tendência positiva de publicações neste início de década, uma vez que só foram computados três anos desse período.

Quanto ao tema Educação moral, desenvolvimento moral e moralidade, podemos observar, também, a ocorrência de um interesse crescente dos pesquisadores pela questão da moralidade, tendo sido encontrados 3 títulos (3,8\% do total nessa subárea) nos anos de 1970, 20 títulos $(25,3 \%)$ na década seguinte, chegando a atingir 33 títulos (41,8\%) nos anos de 1990 e, apenas no início deste decênio, já se contabilizam 23 títulos $(29,1 \%)$ referentes ao tema.

Ao traçarmos um paralelo entre esse dados apresentados e a forma como a ética, a moralidade, a educação moral e os direitos humanos têm sido abordados nos contextos social, educacional e político brasileiro, podemos identificar a possível existência de uma simultaneidade entre a evolução das produções no meio acadêmico e os acontecimentos históricos no Brasil. Nesse sentido, um aspecto marcante a ser ressaltado é que, enquanto as publicações sobre Ética, valores e educação e Educação, cidadania e direitos humanos apresentaram uma evolução importante, em termos de quantidade, já na década de 1980, os trabalhos sobre Educação moral, desenvolvimento moral e moralidade passam a ser preponderantes apenas na década de 1990.

Acreditamos que este fato se deve à maneira como a disciplina educação moral foi instituída no sistema educacional brasileiro. Como já foi mencionado na introdução deste artigo, observamos que essa disciplina esteve vários anos, durante o regime militar, presente no ensino formal, em todos os graus e modalidades de ensino do país, como uma disciplina obrigatória curricular. Após o fim da ditadura, com a tentativa de restabelecimento da democracia, a obrigatoriedade da educação moral no currículo escolar foi legalmente revogada na década de 1990. Dessa forma, não só a educação moral, mas também os termos "moral" e "moralidade" ficaram muito tempo impregnados do sentido dogmático e autoritário que lhes era atribuído durante o período de hegemonia militar. Com o retorno da democracia, esses termos foram paulatinamente recebendo novos sentidos, assim como os estudos na área foram ganhando força - o que pode explicar o aumento significativo de produções neste subtema durante a década de 1990.

Fica patente, também, na análise desses três subtemas, a existência de uma tendência de superação, proporcionalmente, das produções nas três últimas décadas do século XX pelo número de publicações nesta primeira década do XXI.

Vejamos agora, no Gráfico 4, a evolução das publicações sobre Preconceito e educação ao longo do tempo.

Gráfico 4 - Evolução das publicações sobre

Preconceito e educação ao longo do tempo

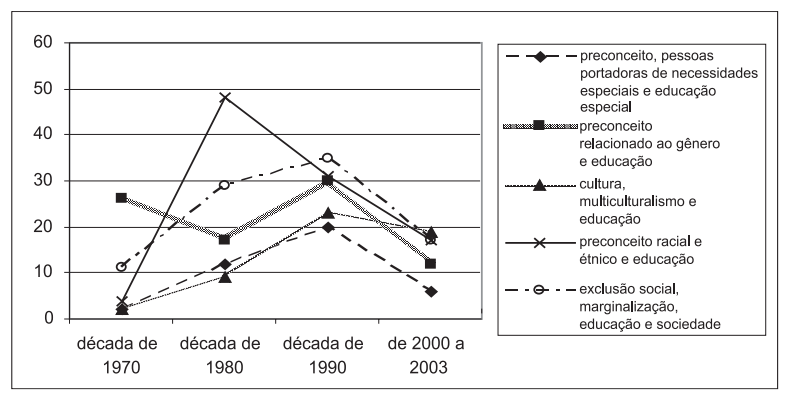

De forma geral, verificamos que houve poucas publicações, durante a década de 1970, de trabalhos 
que abarcassem essa temática, com exceção do subtema Preconceito relacionado ao gênero e educação, que já na década de 1970 aparece com 26 textos (30,6\% das publicações com esse subtema); nos anos 1980, 17 textos (20\%); nos anos de 1990, 30 textos $(35,3 \%)$; e, a partir de 2000, o tema foi abordado em 12 textos $(14,1 \%)$.

Acreditamos que esse número expressivo de estudos sobre gênero, já na década de 1970, esteja relacionado com a história do movimento feminista no Brasil. Segundo Pinto (2003), desde o fim do século XIX as mulheres brasileiras têm lutado por mais direitos; mas após terem conquistado o direito de votar e de serem votadas, em 1930, houve um período de silêncio nas reivindicações femininas. Essa "suspensão" perdurou até o final da década de 1960, quando, após uma fase de opressão causada pela ditadura militar, o movimento feminista volta a ganhar força, tornando-se uma das vozes mais importantes na luta pela anistia e pela volta da democracia no Brasil. Assim, acreditamos poder traçar um paralelo entre o ressurgimento do feminismo na década de 1970 e a publicação de textos sobre preconceito relacionado ao gênero e educação. Nesse período, inclusive, uma das grandes causas defendidas pelo movimento feminista foi a igualdade entre homens e mulheres no acesso à educação e ao mercado de trabalho. Esses dados apontam para o potencial de influência da experiência cotidiana e das transformações sociais sobre a educação e a construção do conhecimento científico.

Nos demais subtemas avaliados pela pesquisa, ocorreu um salto significativo de publicações a partir da década de 1980.

Entre eles, um subtema que merece destaque é Preconceito racial e étnico e educação. Os dados revelam um ápice do interesse em relação ao assunto na década de 1980, com 48 títulos tabulados (48\% do total de textos nesse subtema), diante de apenas 4 títulos (4\%) na década de 1970. Nos anos de 1990, encontramos 31 trabalhos (31\%), e 17 títulos (17\%) entre 2000 e 2003. Esses dados podem ser articulados com o fato de o movimento negro ter ganhado força no Brasil no final da década de 1970. Em 1978, a fundação, em São Paulo, do Movimento Negro Unificado, vem denunciar a discriminação aos negros, as desigualdades sociais e econômicas resultantes do racismo, e lutar pelo reconhecimento social de uma identidade negra. Certamente, a esse fato relaciona-se a existência de uma produção relevante de trabalhos sobre preconceito racial e étnico na escola, especialmente na década seguinte, de 1980.

O subtema Exclusão social, marginalização, educação e sociedade apresenta um pico de produção nos anos de 1990, com 35 títulos publicados (38,9\% do total nessa subárea). Na década anterior, porém, também se produziu um número relevante de trabalhos (27 títulos, 30\%), e nestes três anos iniciais do século XXI já pudemos encontrar 17 estudos (18,9\%). No fim da lista, encontra-se a década de 1970, durante a qual foram publicados 11 títulos $(12,2 \%)$. Verificamos, assim, que este subtema tem sido alvo de interesse de pesquisadores principalmente desde os anos de 1980 , o que pode ser tomado como consequiência do reconhecimento das necessidades de uma sociedade perpassada pela acentuada desigualdade social, a qual se reflete no sistema educacional.

As publicações sobre o subtema Cultura, multiculturalismo e educação obtiveram um crescimento importante somente a partir da década de 1990, com a produção de 23 títulos (43,4\% do total nessa subárea), e nos anos 2000, com 19 publicações $(35,8 \%)$. Nos anos de 1970, apenas 2 títulos $(3,8 \%)$ foram contabilizados, e nos anos de 1980, 9 trabalhos (17\%) foram selecionados em nossa pesquisa.

Como anteriormente se afirmou, por muito tempo a sociedade brasileira disseminou, por intermédio de seus meios de comunicação e até mesmo pela escola, a noção de que o Brasil tinha como característica uma cultura uniforme. Assim, as várias culturas existentes foram camufladas por uma falsa idéia de igualdade. $\mathrm{O}$ recrudescimento do processo de globalização, ocorrido a partir de meados da década de 1980, repercutiu no embate explícito das culturas, levando as sociedades a admitir a existência, dentro dos próprios países, de importante diversidade cultural e racial. Assim, passou-se a divulgar a idéia segundo a qual devemos re- 
conhecer, valorizar e pesquisar a enorme variedade cultural brasileira, pois a identidade nacional é feita dessas contribuições multiculturais e multirraciais. A produção acadêmica acompanhou essa mudança, reconhecendo, primeiramente, o multiculturalismo como uma das grandes questões de nossa época e, em seguida, a escola como um campo estratégico para o desenvolvimento do respeito à diversidade cultural.

Em relação ao subtema Preconceito, pessoas portadoras de necessidades especiais e educação especial, apesar de a partir de 2000 terem sido encontrados 6 textos $(15 \%)$, observamos que a maior parte dos títulos situa-se na década de 1990, com 20 trabalhos (50\% do total na área). Ao se comparar a publicação do subtema na década de 1980 (12 títulos, 30\%) com os anos de 1970 (2 títulos, 5\%), percebe-se a existência de um interesse crescente pelo tema. Reportando-nos à história, podemos encontrar dados passíveis de ajudar a explicar este fato. A partir do início da década de 1990, documentos - como a Declaração de Salamanca, de 1994 - vieram a oficializar o termo "inclusão" no campo educacional. Esses documentos, que tomaram por base, inicialmente, a Declaração Universal dos Direitos Humanos, de 1948, foram estabelecidos pela Conferência Mundial sobre Educação para Todos, de 1990.

Assim, nos países mais desenvolvidos, o Movimento de Inclusão Social e Educacional ganhou impulso, acabando por ecoar no Brasil. No Brasil, as novas Leis de Diretrizes e Bases da Educação, do final do século XX, discorrem sobre a inclusão da criança com necessidades especiais na escola pública. Esse movimento vem paulatinamente ganhando força e muitas escolas particulares também já tomam iniciativas inclusivas. Dessa forma, a década de 1990 foi um momento importante para seu fortalecimento, baseado na aspiração a um novo modelo de sociedade. No Brasil atual, apesar de a inclusão ainda ser um grande desafio para a sociedade e a educação, acreditamos que esses acontecimentos tenham marcado o aumento significativo, nos anos de 1990, de textos sobre preconceito à pessoa com necessidade especial, educação especial e inclusão.
A análise numérica das 570 publicações selecionadas nesta pesquisa revela que, tanto no grupo Ética, moral e educação como no grupo Preconceito e educação, tem sido relevante o número de trabalhos publicados neste início do século XXI, de forma que, provavelmente, esta década superará as anteriores em número de produções. Atribuímos esse aumento de publicações tanto ao supracitado incremento no número de periódicos, quanto ao fato de esses temas terem sido foco de discussão em nossa sociedade, o que repercute no contexto educacional. As reformas educacionais da atualidade - como os PCNs de 1997 e 1998 - têm sido, inclusive, estruturadas buscando atender à demanda emergente.

É possível supor-se, a partir da contextualização dos dados coletados pela pesquisa, que a valorização desses temas por meio de propostas educacionais oficiais incentive a produção de pesquisas na área.

Estudos sobre essas propostas, no entanto, têm sido ainda poucos. Em um levantamento quantitativo e qualitativo de dissertações, teses e artigos publicados entre 1990 e 2003 que versassem sobre ética, educação e outros temas relacionados, La Taille, Souza e Vizioli (2004) verificaram que, de 28 artigos analisados, apenas 6 se remetem aos PCNs. Os autores justificam essa ausência de trabalhos pela escassez de propostas pedagógicas sobre a formação ética dos alunos.

\section{Aspectos metodológicos das produções: tipos de publicação, procedimentos e populações estudadas}

Entre os 570 textos encontrados por esta pesquisa, constatamos a predominância de artigos, com 423 textos $(74,2 \%$ do total), seguida das resenhas, com 109 trabalhos $(19,1 \%)$. O restante dos estudos foi apresentado na forma de conferência, relato de experiência, carta e entrevista (37 trabalhos, 6,7\%).

Quanto ao tipo de estudo, dividimos os títulos encontrados em dois grandes grupos: "pesquisa empírica, pesquisa de campo" e "discussão teórica, pesquisa bibliográfica”. Encontramos, tanto nos trabalhos sobre Ética, moral e educação como nos que 
abordam o Preconceito e a educação, um predomínio de trabalhos bibliográficos e de discussões teóricas (370 trabalhos, $65 \%$ do total pesquisado) em relação às pesquisas de campo e empíricas (200 estudos, 35\%).

Com relação ao tipo de estudo conforme cada subtema, a maior parte dos títulos encontrados também está concentrada no tipo de estudo "discussão teórica, pesquisa bibliográfica". Apenas em um subtema esse resultado não pode ser observado: Educação moral, desenvolvimento moral e moralidade, que apresenta 44 títulos (54,3\% do total de artigos sobre esse subtema) na forma de pesquisa empírica e $37(45,7 \%)$ na de discussão teórica, pesquisa bibliográfica.

Observamos uma grande diferença de títulos relacionados aos tipos de pesquisas referente a alguns subtemas, apresentando-se as discussões teóricas e pesquisas bibliográficas com um número bem maior de trabalhos publicados que as pesquisas de caráter empírico. Os subtemas que apresentam diferenças numéricas importantes quanto ao tipo de estudo são: Ética, valores e educação, com 18 pesquisas empíricas (22\%) e 66 estudos bibliográficos (79\%); Educação, cidadania e direitos humanos, com 4 estudos empíricos (11\%) e 33 bibliográficos (79\%); Cultura, multiculturalismo e educação, com 11 estudos empíricos (21\%) e 42 bibliográficos (79\%).

Os demais subtemas - Preconceito relacionado ao gênero e educação; Preconceito racial e étnico e educação; Preconceito, pessoas portadoras de necessidades especiais e educação especial e Exclusão social, marginalização educação e sociedade - apresentaram uma média de $35 \%$ de pesquisas empíricas e $65 \%$ de estudos teóricos.

As pesquisas relacionadas ao subtema Educação moral, desenvolvimento moral e moralidade apresentam um maior número de pesquisas empíricas, ao passo que o subtema Ética, valores e educação possui mais estudos bibliográficos. Anteriormente, neste texto, citamos Cortina (2003), que distingue moral e ética afirmando que, enquanto esta é um saber filosófico, aquela faz parte da vida cotidiana das sociedades e dos indivíduos, e não foi inventada pelos filósofos. A moral tem a ver com a vida social, enquanto a ética tem "sobrenomes filosóficos". A pesquisa que ora se realiza corrobora essa idéia, uma vez que a maior parte dos estudos relacionados à moralidade são empíricos, enquanto os que tratam da questão da ética são teóricos.

Outra hipótese que se pode levantar a partir dos resultados deste trabalho é de que a psicologia do desenvolvimento tem contribuído de foram substancial com a realização de pesquisas empíricas na área da moralidade, a ponto de atualmente já se ter consolidado uma nova área no âmbito da psicologia: a psicologia moral, que tem como principais representantes Piaget (1994) e Kohlberg (1992).

Esses dados coincidem com a pesquisa de $\mathrm{La}$ Taille, Souza e Vizioli (2004), a qual identificou que, no período compreendido entre 1990 e 2003, apenas um terço das publicações sobre ética são referentes a estudos empíricos - entre essas poucas, a maioria é da área da psicologia moral.

Neste estudo, empregamos o termo metodologia para indicar os procedimentos de pesquisa, como a utilização de questionários, entrevistas, instrumentos padronizados, entre outros meios de obtenção de dados. Nos trabalhos que avaliamos, como acabamos de demonstrar, a maior parte utiliza-se de revisão bibliográfica como metodologia (370 publicações são discussões teóricas ou pesquisas bibliográficas). Nos trabalhos que envolveram pesquisa de campo (200), encontramos variados procedimentos de pesquisa, como entrevistas, questionários, relatos de experiência, e utilização de instrumentos padronizados, como testes, escalas, histórias e dilemas, entre outros. Para cada título encontrado, fizemos referência, em nosso banco de dados, apenas a um tipo de procedimento metodológico, mesmo quando no texto aparece mais de um. Seguimos, para isso, as indicações presentes nos textos e resumos, nos quais geralmente se salienta a metodologia principal. Esses dados podem ser visualizados no Gráfico 5.

Conforme demonstra o Gráfico 5, verificamos que os procedimentos mais utilizados nas pesquisas empíricas, tanto no grupo Preconceito e educação como no grupo Ética, moral e educação, são os questionários e as entrevistas, com $38,8 \%$ e $48,5 \%$, res- 
pectivamente, do total das pesquisas empíricas selecionadas em cada tema. Em seguida estão os instrumentos padronizados, incluindo testes e escalas, com 12,7\% da freqüência do grupo Preconceito e educação e $16,7 \%$ do grupo Ética, moral e educação. Posteriormente, encontramos as observações, os relatos de experiência e outros tipos de procedimentos. Notamos que, em 18,7\% dos resumos que afirmam utilizar a pesquisa empírica sobre Preconceito e educação e em 10,6\% dos resumos sobre Ética, moral e educação, esses dados sobre procedimentos metodológicos não são informados.

Gráfico 5 - Porcentagem de utilização dos diferentes procedimentos nas pesquisas empíricas

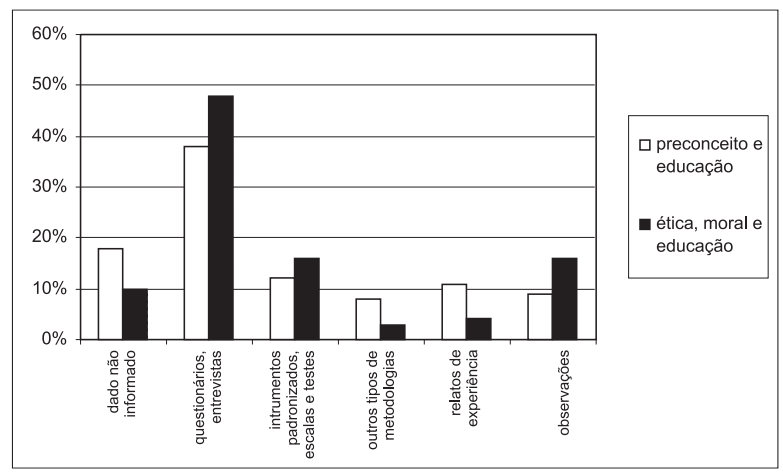

No Gráfico 6, apresentamos as principais populações pesquisadas nos estudos de natureza empírica:

Gráfico 6 - Populações estudadas nas pesquisas empíricas

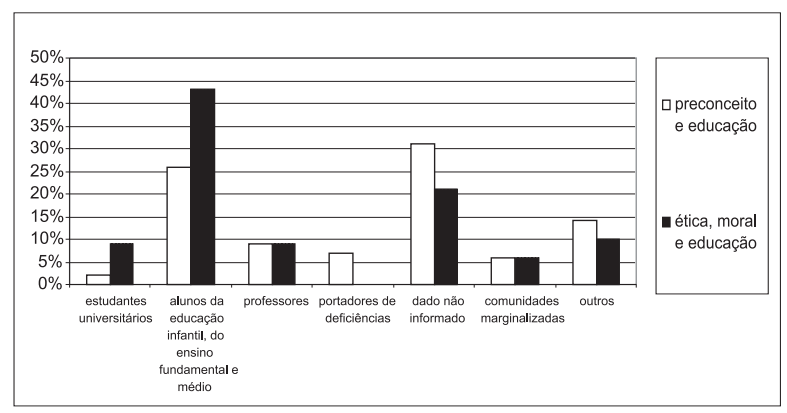

Grande parte das pesquisas dos grupos Preconceito e educação (26,9\%) e Ética, moral e educação $(43,9 \%)$ selecionou como população-alvo alunos de educação infantil e do ensino fundamental e médio. Poucos estudos, nos dois grupos, tiveram como sujeitos alunos universitários, o que demonstra a existência de poucas pesquisas empíricas que focalizam a ética e o preconceito no ensino de nível superior. A freqüência com que os professores participaram dos trabalhos como sujeitos foi de cerca de 9\%, tanto nos estudos sobre Preconceito e educação quanto nos sobre Ética, moral e educação. Os portadores de deficiências aparecem como sujeitos apenas dos estudos que abordam a questão do preconceito, com 7,5\% de freqüência. Há também trabalhos que têm outros tipos de sujeitos, como comunidades marginalizadas. Um número expressivo de estudos (31,3\% no grupo sobre Preconceito e educação e $21,2 \%$ no grupo sobre Ética, moral e educação) não identifica, nos resumos, os sujeitos pesquisados.

O número de sujeitos participantes dos estudos empíricos é identificado na Tabela 2.

Tabela 2 - Número de sujeitos participantes das pesquisas empíricas

\begin{tabular}{|c|c|c|c|}
\hline \multirow[b]{2}{*}{$\begin{array}{c}\text { Número de sujeitos } \\
\text { participantes }\end{array}$} & \multicolumn{2}{|c|}{ TEMA } & \multirow[b]{2}{*}{ Total } \\
\hline & $\begin{array}{l}\text { Preconceito } \\
\text { e educação } \\
\end{array}$ & $\begin{array}{l}\text { Ética, valores } \\
\text { e educação }\end{array}$ & \\
\hline \multirow{2}{*}{$\begin{array}{l}\text { dado não informado } \\
\text { no resumo }\end{array}$} & 102 & 41 & 143 \\
\hline & $76,1 \%$ & $62,1 \%$ & $71,5 \%$ \\
\hline \multirow{2}{*}{ 1-50 sujeitos } & 11 & 10 & 21 \\
\hline & $8,2 \%$ & $15,1 \%$ & $10,5 \%$ \\
\hline \multirow{2}{*}{ 51-100 sujeitos } & 1 & 5 & 6 \\
\hline & $0,7 \%$ & $7,6 \%$ & $3 \%$ \\
\hline \multirow{2}{*}{ 102-200 sujeitos } & 8 & 4 & 12 \\
\hline & $6 \%$ & $6,1 \%$ & $6 \%$ \\
\hline \multirow{2}{*}{ 201-400 sujeitos } & 5 & 4 & 9 \\
\hline & $3,8 \%$ & $6,1 \%$ & $4,5 \%$ \\
\hline \multirow[b]{2}{*}{ acima de 401 sujeitos } & 7 & 2 & 9 \\
\hline & $5,2 \%$ & $3 \%$ & $4,5 \%$ \\
\hline \multirow{2}{*}{ Total } & 134 & 66 & 200 \\
\hline & $100 \%$ & $100 \%$ & $100 \%$ \\
\hline
\end{tabular}

Na Tabela 2, observamos, primeiramente, a predominância de trabalhos que não apontam em seu resumo o número de sujeitos participantes. No grupo Preconceito e educação, $76,1 \%$ dos estudos não forneceram esse dado, enquanto no grupo Ética, moral e educação essa informação foi omitida em $62,1 \%$ dos trabalhos. Entre os que informaram o número de su- 
jeitos, houve a supremacia de pesquisas com o máximo de 50 participantes. Entre os demais textos, pôdese identificar uma variação importante no número de sujeitos.

De forma geral, constatamos, com base nos dados relativos aos aspectos metodológicos dos estudos selecionados, que muitos dos resumos pesquisados estão incompletos, deixando de fornecer dados importantes ao leitor, como procedimentos metodológicos, proveniência da amostra e número de sujeitos pesquisados. A ausência desses dados dificulta o trabalho de pesquisadores da área, e é um importante aspecto a ser considerado no momento em que a divulgação científica tem se expandido cada vez mais, com a utilização de indexadores e meios de divulgação eletrônica.

\section{Conclusão}

Procuramos, com esta pesquisa, realizar um estudo bibliográfico quantitativo referente ao tema Ética e preconceito no âmbito da educação escolar, em periódicos nacionais das áreas de educação, psicologia e filosofia, publicados a partir da década de 1970 até $\mathrm{o}$ ano de 2003. Pesquisamos exaustivamente esses periódicos, a fim de que nossa investigação contemplasse os assuntos e subtemas mais relevantes em relação ao tema central. Verificamos que tanto o tema Ética e moral quanto o tema Preconceito abrangem diversos aspectos que fazem parte do cotidiano escolar. Dentro de Ética, moral e educação, encontramos trabalhos sobre ética, valores, educação moral, desenvolvimento moral, valores, cidadania e direitos humanos. Em relação ao tema Preconceito e educação, encontramos estudos sobre a questão do preconceito racial, do preconceito relacionado ao gênero, da exclusão social, do preconceito ao portador de necessidades especiais, da inclusão e da pluralidade cultural.

Algumas revistas se destacaram pelo fato de apresentarem um maior número de produções científicas publicadas com o tema, no período que compreende este estudo. As revistas em questão foram: Cadernos de Pesquisa; Educação e Sociedade; Revista Brasi- leira de Educação; Psicologia. Reflexão e Crítica; $\mathrm{Ca}$ dernos CEDES e Revista da Faculdade de Educação da USP. Cruzando os dados referentes aos subtemas selecionados e às revistas pesquisadas, observamos, entre os estudos publicados, a predominância de alguns subtemas em determinadas revistas.

No período de tempo que compreende este estudo, especialmente nas três últimas décadas (1980, 1990 e início de 2000), houve uma preocupação, por parte dos pesquisadores, com questões éticas e a problemática da diversidade e suas relações com a educação escolar, contribuindo, assim, para o avanço das discussões na área. Supomos que o aumento das publicações a partir da década de 1980 ocorreu tanto por um aumento da divulgação científica de um modo geral, impulsionado pela fundação de novos periódicos (grande parte das revistas pesquisadas foi lançada nas décadas de 1980 e 1990), como também pela existência de uma inter-relação entre a evolução das produções no meio acadêmico e os acontecimentos históricos no Brasil. Dessa forma, enfocamos a relação entre a evolução cronológica das publicações selecionadas em nossa pesquisa e a maneira como a ética, a moralidade, a educação moral, o preconceito, a exclusão social, a diversidade cultural e os direitos humanos têm sido abordados no contexto social, educacional e político brasileiro.

Quanto aos tipos das publicações veiculadas nas revistas pesquisadas, verificamos a predominância de artigos em relação aos demais tipos de trabalhos resenhas, conferências, relatos de experiência, cartas e entrevistas.

Constatamos, ainda, que a maioria dos trabalhos realizou estudos teóricos e pesquisas bibliográficas, em detrimento das pesquisas empíricas e de campo. Entre os oito subtemas encontrados, apenas no subtema Educação moral, desenvolvimento moral e moralidade foi predominante a realização de pesquisa de campo. Supomos que este dado se deva ao fato de os estudiosos considerarem a moral em relação aos valores, princípios e regras legitimados e vivenciados na vida cotidiana, e a ética como uma reflexão sobre tais valores, princípios e regras. Outra hipótese é a de 
que a psicologia moral tenha contribuído com a realização de pesquisas empíricas na área da moralidade.

No que diz respeito aos procedimentos metodológicos utilizados nas pesquisas de campo, verificamos que os mais freqüentes são os questionários e as entrevistas. Quanto aos sujeitos participantes das investigações, constatamos que os pesquisadores têm enfocado muito mais os alunos do ensino fundamental e médio do que professores, funcionários, alunos do ensino superior e outras populações.

Em relação ao tamanho das amostras pesquisadas, observamos a existência de uma variação importante no número de sujeitos, mas que entre os resumos que fornecem esse dado prevalecem as pesquisas com no máximo 50 sujeitos.

Constatamos, também, que muitos dos resumos pesquisados omitem dados importantes para o leitor, relativos aos procedimentos metodológicos, à procedência da amostra e ao número de sujeitos pesquisados. Salientamos a necessidade de os estudiosos atentarem para a elaboração dos resumos no momento de publicar suas produções, uma vez que a divulgação científica tem se expandido cada vez mais com a utilização de indexadores e meios de divulgação eletrônica, e o resumo é um instrumento de fundamental importância para o pesquisador selecionar trabalhos.

A fim de colaborar com futuros estudos acerca do tema, elaboramos um índice dos textos pesquisados, com base nos principais subtemas selecionados. Esse índice, juntamente com o material que foi coletado nas bibliotecas e que está organizado em pastas, tornou-se patrimônio da Faculdade de Ciências e Tecnologia da UNESP, campus de Presidente Prudente, e funcionará como banco de dados para pesquisadores, ligados a diversas áreas do conhecimento, que possuam interesse em estudar os temas Ética e Preconceito, e seus diversos subtemas. Esta pesquisa, portanto, apesar de estar encerrada do ponto de vista dos objetivos a que se propôs, não termina aqui. Por tratar-se de uma pesquisa quantitativa, seria muito profícua sua retomada, por meio de outros estudos. A abordagem dos conteúdos dos artigos levantados, para que se realize sua análise qualitativa, é um processo necessário para a reelaboração dos dados levantados, assim como o aprofundamento de certos conteúdos. Este trabalho pode, portanto, e deve constituir-se em caminho para estudos posteriores.

\section{Referências bibliográficas}

BRASIL. Ministério da Educação. Parâmetros curriculares nacionais: primeiro e segundo ciclos do ensino fundamental. Brasília: Secretaria de Ensino Fundamental, 1997.

\section{Parâmetros Curriculares Nacionais: terceiro e quarto}

ciclos do ensino fundamental. Brasília: Secretaria de Ensino Fundamental, 1998.

BUXARRAIS, M. R. La formación del professorado en educación en valores: propuesta y materiais. Bilbao: Desclée de Brouwer, 1997.

CORTINA, A. O fazer ético: guia para a educação moral. São Paulo: Moderna, 2003.

DaMATTA, R. O que faz o brasil, Brasil? Rio de Janeiro: Rocco, 1991.

KOHLBERG, L. Psicologia del desarrollo moral. Bilbao: Desclée de Brouwer, 1992.

LA TAILLE, Y. de; SOUZA, L. S.; VIZIOLI, L. Ética e educação: uma revisão da literatura educacional de 1990 a 2003. Educação $e$ Pesquisa, São Paulo, v. 30, n. 1, p. 91-108, 2004.

LEPRE, R. M. A indisciplina na escola e os estágios de desenvolvimento moral na teoria de Jean Piaget. Dissertação (Mestrado) Faculdade de Filosofia e Ciências da Universidade Estadual Paulista, campus de Marília, 2001.

PINTO, C. R. J. Uma história do feminismo no Brasil. São Paulo: Fundação Perseu Abramo, 2003.

PIAGET, J. O juízo moral na criança. São Paulo: Summus, 1994. SUBIRATS, M. A educação do século XXI: a urgência de uma educação moral. In: IMBERNÓN, F. (Org.). A educação no século XXI: os desafios do futuro imediato. Porto Alegre: Artes Médicas Sul, 2000.

VALENTE, A. L. A propósito dos Parâmetros Curriculares Nacionais sobre a pluralidade cultural. Revista Educação, Universidade Federal de Santa Maria, v. 26, n. 1, 2001. Disponível em: <http:// www.ufsm.br/ce/revista/revce/2001/01/a1.htm>. Acesso em: 4 fev. 2005. 
ALESSANDRA DE MORAIS SHIMIZU, doutora em educação pela Universidade Estadual Paulista, campus de Marília, é professora e diretora da Faculdade de Ciências da Saúde de Garça, São Paulo. Publicou recentemente: Defining Issues Tests: fidedignidade da versão brasileira e ponderações acerca de seu uso em pesquisas sobre moralidade (Psicologia. Reflexão e Crítica, Porto Alegre, Ed. UFRGS, v. 17, n. 1, p. 5-14, 2004); em co-autoria com URANO, Meire Miwa. Defining Issues Tests 1 y 2: cálculo de confiabilidad de las versiones castellanas y consideraciones a cerca de su uso en estudios sobre moralidad (Investigaciones en Psicología, Revista del Instituto de Investigaciones, Buenos Aires, Argentina, Universidad de Buenos Aires, v. 9, n. 2, p. 41-57, 2004); com MENIN, Maria Suzana de Stefano. Representaciones sociales de ley, justicia e injusticia: un estudio con jóvenes argentinos y brasileños utilizando la técnica de evocación libre de palabras $(R e$ vista Latinoamericana de Psicologia, Bogotá, Colômbia: Fundación para el Avance de la Psicologia, v. 36, n. 3, p. 431-444, 2004). Áreas de pesquisa: psicologia do desenvolvimento moral e representações sociais de aspectos sociomorais. E-mail: ashimizu@ flash.tv.br

ANA PAULA CORDEIRO, doutora em educação pela Universidade Estadual Paulista, campus de Marília, é professora assistente da Faculdade de Filosofia e Ciências da mesma instituição. Publicou recentemente: O lúdico e a memória presentes nos exercícios de escrita das alunas das oficinas de teatro da UnatiUnesp de Marília (In: SEMANA DA MULHER: lutas do passado, conquistas do presente e perspectivas futuras, 4. Marília: FFCUNESP, 2005, p. 25); Oficinas de teatro da UNATI-UNESP de
Marília e a importância da contribuição feminina: memória, improviso e criação (In: SEMANA DA MULHER: lutas do passado, conquistas do presente e perspectivas futuras, 4. 2005, Marília. RESUMOS. FFC-UNESP, 2005, p. 24); em co-autoria com Alessandra Morais Shimizu, Injustiças no cotidiano escolar (In: REUNIÃO DA ANPEd, 27. Caxambu, MG., 2004. 1 CD-ROM). E-mail: pascord@uol.com.br

MARIA SUZANA DE STEFANO MENIN, doutora em psicologia do escolar pela Universidade de São Paulo (USP), com pós-doutorado na École des Hautes Études en Sciences Sociales e na Université René Descartes, em Paris. Livre-docente em psicologia da educação e do desenvolvimento pela Universidade Estadual Paulista (UNESP), é professora da Faculdade de Ciências e Tecnologia dessa universidade, no campus de Presidente Prudente, e foi coordenadora da Pós-Graduação em Educação - Formação de Professores da mesma instituição. Publicou recentemente: Atitudes de adolescentes frente à delinqüência como representações sociais (Psicologia. Reflexão e Crítica, Porto Alegre, Ed. UFRGS, v. 1, n. 16, p. 125-135, 2003); Representaciones sociales de la ley en adolescentes de una ciudad del estado de São Paulo, Brasil (Educar, Universidad Autònoma de Barcelona, v. 31, p. 89108, 2003); Escola e educação moral (In: SCHUMACHER, Aluisio Almeida (Org.). Pedagogia cidadã. Cadernos de Formação. Ética e Cidadania. 2. ed. São Paulo, 2004). E-mail: menin@prudente.unesp.br.

Recebido em maio de 2005 Aprovado em outubro de 2005 
lato de la pesquisa con estudiantes de Río de Janeiro es presentado, bien como su metodología - que envuelve grupos focales y observados - y una revisión de literatura aparentada al problema, al cual antecede la exposición de resultados obtenidos por medio de los grupos focales realizados. Los datos sistematizados se inclinan a fortalecer la hipótesis principal: la escuela parece un elemento dubio y cuestionable para la fracción más "excluída” de los estudiantes oídos. Sin embargo, hay circunstancias que confunden este cuadro, destacando la experiencia escolar como un aspecto central del valor atribuído por los estudiantes a la escuela y, de cierta forma, contrabalanceando los efectos disruptivos de un cuadro económico de agudos conflictos sociales, asociados a modelos de desigualdad social extremos y duraderos.

Palabras claves: sociología de la educación; valor social de la educación; juventud y educación; exclusión social, sagrado social

Cynthia Paes de Carvalho

Contextos institucionais e escolarização: uma hipótese de classificação das escolas da rede privada de educação básica

Em interlocução com a literatura da sociologia da educação sobre a transmissão intergeracional do patrimônio cultural nas camadas médias, particularmente no que toca aos investimentos educacionais, foi construída uma tipologia das escolas e das trajetórias escolares da educação básica. A partir de uma hipótese de classificação das escolas da rede privada de ensino no Rio de Janeiro, são descritos os diferentes percursos escolares encontrados e são discutidos alguns resultados da análise dos dados referentes ao grupo estudado. Conclui-se ressaltando o potencial heurístico da caracterização de- senhada, no sentido de ampliar a compreensão do conjunto dos estabelecimentos de ensino básico e enriquecer as possibilidades de análise para além da distinção do caráter público ou privado das escolas.

Palavras-chave: escolas; trajetórias; estratégias

\section{Institutional contexts and} schooling: a hypothesis for the classification of private primary schools

On the basis of a dialogue with the literature of the sociology of education on the inter-generational transmission of cultural patrimony among the middle classes, particularly with respect to educational investment, a typology of schools and primary school trajectories was constructed. Based on a hypothesis for the classification of private schools in Rio de Janeiro, the different school trajectories found are described and some results of the analysis of the data referring to the group studied are discussed. The conclusion highlights the heuristic potential of the characterisation designed in the sense of deepening the understanding of the set of primary school establishments and enriching the possibilities of analysis by going beyond the distinction between the public and private character of the schools.

Key-words: schools; trajectories; strategies

Contextos institucionales y de escolaridad: una hipótesis de clasificación de las escuelas privadas de primera enseñanza En la interlocución con la literatura de la sociología de la educación sobre la transmisión intergeneracional del patrimonio cultural en las capas medias de la sociedad, particularmente lo que concierne a las inversiones en la educación, fue construída una tipología de las escuelas y de las trayectorias escolares de la educación básica. A partir de una hipótesis de clasificación de las escuelas privadas de enseñanza en Río de Janeiro, son descriptos los diferentes trayectos escolares, encontrados y discutidos algunos resultados del análisis de los datos referentes al grupo estudiado. Se concluye resaltando el potencial heurístico de la caracterización delineada, en el sentido de ampliar la comprensión del conjunto de los establecimientos de enseñanza básica y enriquecer las posibilidades de análisis, para lejos de la distinción del carácter público o privado de las escuelas.

Palabras claves: escuelas; trayectorias; estrategias

Alessandra de Morais Shimizu, Ana Paula Cordeiro e Maria Suzana De Stefano Menin

Ética, preconceito e educação: características das publicações em periódicos nacionais de educação, filosofia e psicologia entre 1970 e 2003

Apresenta um estudo bibliográfico referente ao tema "ética e preconceito" no âmbito da educação escolar em periódicos nacionais das áreas de educação, psicologia e filosofia a partir da década de 1970 até o ano de 2003. No total, foram categorizados e analisados 570 textos. Constatamos que, especialmente, nas três últimas décadas, houve uma preocupação, por parte dos pesquisadores, com questões éticas e a problemática da diversidade e suas relações com a educação escolar. Percebemos, também, que algumas revistas científicas se destacaram por apresentar um maior número de produções científicas publicadas com o tema e no período que compreende este estudo. Além disso, a maioria dos trabalhos realizou estudos teóricos e pesquisas bibliográficas em detrimento às pesquisas empíricas. Foi elaborado um índice dos textos pesquisados que, juntamente com o material coletado, funcio- 
nará como banco de dados para pesquisadores, ligados a diversas áreas do conhecimento, que possuam interesse em estudar o tema "ética e preconceito" e seus diversos subtemas.

Palavras-chave: ética e educação, preconceito e educação; produção científica

Ethics, prejudice and education: characteristics of publications in national periodicals in Education, Philosophy and Psychology from the 1970's to 2003

Presents a bibliographic study referring to the theme "ethics and prejudice" in the ambit of schooling, in national education, psychology and philosophy periodicals from the 1970's to 2003. In total, 570 texts were categorised and analysed. We verified that, especially in the last three decades, researchers have shown a concern for ethical issues and the question of diversity and its relationship with schooling. We also found evidence that some scientific reviews stood out for the large number of scientific productions published on the theme during the period covered by this study. In addition to this, the majority of the research projects were theoretical studies and bibliographic reviews to the detriment of empirical research. An index of the texts researched was compiled which, along with the material collected, will serve as a database for researchers from different areas of knowledge who are interested in studying the theme of "ethics and prejudice" and its numerous subthemes.

Key-words: ethics and education; prejudice and education; scientific production

Etica, prejuicio y educación: características de las publicaciones en periódicos nacionales de educación, filosofía y psicología, durante la década de 1970 hasta el año 2003

Presenta un estudio bibliográfico referente al tema "ética y prejuicio" en el ambiente de la educación escolar en periódicos nacionales de las áreas de Educación, Psicología y Filosofía a partir de la década de 1970 hasta el año 2003. En total fueron catalogados y analizados 570 textos. Constatamos que, especialmente, en las tres últimas décadas, hubo una preocupación, por parte de los pesquisadores, con cuestiones éticas y la problemática de la diversidad y sus relaciones con la educación escolar. Notamos también, que algunas revistas científicas se destacaron por presentar un mayor número de producciones científicas, publicadas con el tema y en el período que comprende este estudio. Además de esto, la mayoría de los trabajos realizaron estudios teóricos y pesquisas bibliográficas en detrimento a las pesquisas empíricas. Fue elaborado un indice de los textos pesquisados que, junto con el material colectado, funcionará como banco de datos para pesquisadores, unidos a diversas áreas del conocimiento, que posean interés en estudiar el tema "ética y prejuicio" y sus diversos subtemas.

Palabras claves: ética y educación; prejuicio y educación; producción científica 